\title{
EL TIEMPO DEL ARTE Genitivo objetivo y subjetivo
}

\author{
THE TIME OF ART \\ Objective and Subjective Genitive
}

Sixto J. Castro / sixto@fyl.uva.es

Departamento de Filosofía. Universidad de Valladolid. España

Recibido: 7/2/2020

Aceptado: 19/5/2020

\section{RESUMEN}

Hay diversas formas de analizar la temporalidad de la obra de arte. En este artículo presentamos diversos modos posibles de comprender el elemento temporal de las obras de arte. Por un lado, el tiempo es un marco exterior a las obras, que posibilita ordenarlas, medirlas, etcétera. Por otro el tiempo es una realidad generada por las obras mismas, que no se da sin ellas. Además, las obras de arte tienen un papel importante en la elaboración de cronosofías y en la fundación de una temporalidad histórica determinada.

\section{PALABRAS CLAVE}

Tiempo; acontecimiento; cronosofía; historia

\section{ABSTRACT}

There are several ways to analyze the temporality of the work of art. In this paper I present several possible ways to understand the temporal element of artworks. On the one hand, time is considered as a framework outside the works, which makes it possible to order and measure them, etcetera. On the other hand, time is considered as a reality generated by the works themselves, which does not occur without them. In addition, artworks play an important role in the elaboration of chronosophies and in the foundation of a specific historical temporality.

\section{KEYWORDS}

Time; event; cronosophy; history 
Cuando hablamos de tiempo, hablamos no tanto de un concepto como de un macroconcepto que subsume diferentes teorizaciones desde perspectivas muy diversas: mítica, religiosa, científica, histórica, psicológica, filosófica, etcétera. El tiempo se dice de muchas maneras (Castro, 2002). Igualmente, el concepto de arte abarca realidades diversas, y más aún desde el punto de vista temporal (Castro, 2004). Es tradicional la división, que se remonta a Gotthold Ephraim Lessing (2014), entre artes temporales y espaciales, unas que constitutivamente están dispuestas para narrar el flujo del tiempo y otras que se concentran mejor en el instante, es decir, en el tiempo congelado. Aquellas son el territorio del poeta y estas son el espacio del pintor (Lessing, 2014). Sea esto así o no, esta caracterización de las artes en función de su imitación de lo que sucede en el tiempo, de su posibilidad de pintar el tiempo de un modo u otro, de poner el ser temporal en forma artística, saca a la luz el hecho de que las artes hacen surgir determinadas características o formas de temporalidad que posibilitan una vivencia particular del tiempo, una comprensión específica de este, y establecen determinadas cronosofías que iluminan los marcos temporales en los que nos situamos.

\section{LAS DIVERSAS CARAS DEL TIEMPO}

Cuando hablamos del tiempo, en ocasiones nos referimos a este como si se tratase de un mero contenedor vacío, fluyente, al que se añaden los entes no temporales que, de este modo, se vuelven temporales. El tiempo, así, sería la sucesión misma. Pero también nos referimos a los entes como temporales ellos mismos, es decir, como fundantes de temporalidad, que solo existen en tanto ellos la instauran, sin que se pueda aludir a otra realidad exterior y preexistente a los entes mismos. Hablamos también del tiempo como la medida de la sucesión, como una sucesión significativa (tiempo de salvación), como un conjunto de acontecimientos que se dan dentro de un marco común (mi tiempo), como la organización de los acontecimientos desde una perspectiva cronosófica, es decir, atendiendo a una determinada topología (tiempo del fin), como algo objetivo o subjetivo, etcétera. Para lo que nos interesa, en relación con las artes, podemos resumir esta pluralidad en cuatro concepciones: 
1) En primer lugar, hablamos del tiempo como si se tratase de una estructura externa a los sucesos, independiente de ellos, que posibilita la medida de los eventos y nos permite ordenarlos, orientarlos y lograr la coordinación de esos eventos (sean sucesos físicos, sociales, acciones humanas, etcétera). Hablamos, entonces, de "acontecimientos en el tiempon. El tiempo se comprende como una realidad que puede tener diferentes consideraciones ontológicas (puede ser natural o convencional, objetivo o subjetivo), pero que, en todo caso, no se identifica con los entes a los que cobija. Por ello, puede ser tomado como una regla exterior que puede ser codificada en forma de relojes o de calendarios, cuya medida y ordenación procuran. Estos nos permiten identificar el lapso comparativo, la velocidad, los intervalos, la duración de los diversos acontecimientos $\mathrm{y}$, de este modo, nos posibilitan coordinarlos de cara a establecer relaciones sociales o económicas, o, sobre esa plantilla, convertir la duración de los fenómenos en una mercancía que puede comprarse y venderse. Para ello es necesario que sea numerable y convertible en una variable que forma parte de una ecuación. Lo que existe ocupa un lugar en el tiempo. Así entendido, el tiempo se asemeja a lo que Hans-Georg Gadamer (1991) denomina "tiempo vacío", un "tiempo para algo", un tiempo que se tiene o se cree tener para llenar (p. 48). Este tiempo es el tiempo de la obra de arte tal como la entiende Mikel Dufrenne (2017), a saber, como «una cosa ordinaria, es decir, objeto de una percepción y una reflexión que la distinguen de otras cosas sin otorgarle un tratamiento especial” (p. 40), por ejemplo, el cuadro para un agente de mudanzas o la sinfonía para el programador de conciertos de un auditorio. En cuanto cosa en el mundo, la obra ocupa un tiempo que puede ser medido, que determina la configuración de los espectáculos musicales y literarios, de las celebraciones litúrgicas, incluso una realidad que anima o desanima al público. Asimismo, una obra de arte pertenece a un tiempo dado y tiene tantos años de existencia, fue pintada en tal año, es anterior a esta o a aquella y, por ello, influyó en el estilo de un artista que trabajó después, etcétera. Las obras, de un modo u otro, se sitúan en un tiempo que no son ellas y que es independiente de ellas, sea este espacio cronológico, histórico, o del tipo que fuere.

2) En segundo lugar, hablamos del tiempo como una propiedad inmanente de los sucesos y de los eventos, que son ellos mismos temporales, de tal manera que no hay tiempo independientemente de los 
hechos o de los procesos. Podemos hablar, entonces de "tiempo de los acontecimientos". Desde este punto de vista, el tiempo es engendrado por los fenómenos, por las relaciones entre objetos, sucesos, etcétera y, de este modo, adquiere los caracteres de las realidades que lo originan. Si nace en un contexto de eventos mágicos, el tiempo será mágico, con las características de lo mágico (tiempo propicio, tiempos fastosnefastos, tiempo privilegiado, gran tiempo, tiempo de la fiesta, entre otros). Si el origen es el intercambio socioeconómico de los sujetos, el tiempo deviene mercancía que puede y debe ser comprada y vendida - para lo que es necesario pensarlo en el sentido 1-. Si surge en el espacio de la conciencia, el tiempo mismo es vivencia. Este tiempo ya no es homogéneo, sino que fluye más deprisa o más despacio, a intervalos rítmicos o azarosos y se divide en unidades heterogéneas para dar lugar a diferentes vivencias de conciencia.

En el caso del arte, tratamos ahora del tiempo del "objeto estético", es decir, "la obra de arte percibida en tanto que obra de arte" (Dufrenne, 2017, p. 29), en cuanto que objeto de una percepción estética, como lo es el cuadro para un amante de la pintura o la música para el espectador de un concierto, a saber, "la obra de arte tal como la capta la experiencia estétican (Dufrenne, 2017, p. 47). Se trataría así de un tiempo que va más allá de las determinaciones históricas del tiempo entendido en el sentido 1), puesto que el objeto estético, al ser percibido como tal, muestra que, además de ser cosa, es algo que tiene una temporalidad propia, que él mismo instaura, y que le permite ser contemporáneo de cualquier observador, como es el caso de las ruinas. Al ser percibido, el objeto estético genera la conciencia del tiempo en el sujeto. Ya David Hume, en el Tratado de la naturaleza humana [1738-40] (1992), señalaba que la idea de tiempo no se deriva de una impresión particular distinguible de otras, sino que surge del modo en el que las impresiones se dan a la mente:

Cinco notas tocadas en una flauta nos dan la impresión e idea del tiempo; aunque el tiempo no sea una sexta impresión, que se presente a sí misma al oído o a cualquier otro de los sentidos. $\mathrm{Ni}$ es una sexta impresión que la mente por reflexión encuentre en sí misma (p. 86).

Para los fenomenólogos, la música ha sido el ejemplo fundamental a la hora de explicar el hecho de que el ser humano es memoria y 
anticipación, retención del pasado y protención del futuro. Es la música misma la que pone en primer plano la temporalidad de la conciencia, porque ella misma ejemplifica esa temporalidad que no se identifica con una serie lineal de instantes homogéneos, externos y medibles que posibilitan organizar esquemas. Este es el que Gadamer (1991) denomina tiempo "lleno", "propio», que es descriptible en analogía con el tiempo de la fiesta (o de la obra de arte): no se trata de un tiempo vacío que la fiesta llene, sino que la fiesta inaugura el tiempo y hace que devenga festivo, de modo análogo a como hace la obra de arte, con la que el sujeto establece una relación dialogal. El carácter extracotidiano de la experiencia estética nos sumerge en un tiempo diverso, constituido por fragmentos distintos, heterogéneos, unos llenos y plenificantes y otros vacíos para llenar. Así, por ejemplo, la música, "una suerte de temporalidad encantada" (Jankélevitch, 2005, p. 153), ${ }^{1}$ crea un oasis en el desierto, una isla feliz en el océano de la cotidianidad, un eterno presente, un universo aparte y una totalidad (Jankèlevitch, 2005).

3) Hablamos también del tiempo mediante la elaboración de cronosofías, es decir, topologías del tiempo, imágenes o mapas conceptuales que nos permiten situar los acontecimientos en un marco específico que viene determinado por los mismos acontecimientos. Las cronosofías nos permiten concebir el tiempo como dotado de una forma y/o una dirección, es decir, como progresivo o regresivo, reversible o irreversible, lineal o circular, lleno o vacío, continuo o discontinuo, homogéneo o heterogéneo, finito o infinito, etcétera. Por ejemplo, la direccionalidad del tiempo se pinta de modos diversos en la música. En el caso de la música tonal, tenemos un carácter progresivo, en la medida en que la música se nutre de la memoria, pero se orienta a la anticipación: hay una teleología, somos conducidos a un fin (teleogogía), cosa que no sucede en cierta música de vanguardia, que carece de dirección (Meyer, 1967). Si en la música prevanguardista podemos esperar y anticipar protentivamente determinados movimientos, cadencias, modulaciones, etcétera, la música de vanguardia carece de telos anticipable y pinta el tiempo como una sucesión de instantes que se suceden sin que pueda

1 Así lo señala Thomas Mann (1993): "Una obra de concierto sin pretensiones dura unos siete minutos, ¿no es verdad?, y esos minutos constituyen algo en sí, tienen un principio, un fin, se destacan y están, en cierto modo, garantizados de no deshacerse imperceptiblemente en el ritmo monótono del tiempo. [...] La música despierta el tiempo, nos despierta al disfrute más refinado del tiempon (p. 19)

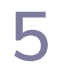


establecerse un mapa que los unifique en modo alguno. Ejemplifica una cronosofía no lineal o continua, sino reticular y discontinua. En ocasiones, todo lo que tenemos es un tiempo denso, como en 4' 33", de John Cage, donde la música no tiene más atributos que la temporalidad misma. Esta caracterización es aplicada por Gaston Bachelard (1986) a la poesía, en la que se encuentran elementos de un tiempo detenido, que no sigue la medida "de un tiempo que llamaremos vertical para distinguirlo del tiempo común que huye horizontalmente" (p. 132). Los elementos teleogógicos se dan también en las composiciones literarias, teatrales y fílmicas, es decir, en todas aquellas artes en las que cada fase contiene un futuro que se va anticipando y un final tal que ya no hay un después del tiempo de la obra (Ingarden, 1987).

4) Finalmente, las obras de arte establecen relaciones históricas con sus precedentes y sus consecuentes. Para que algo sea una obra de arte se supone que ha de ser considerado en el modo en que fueron considerados sus antepasados históricos (Levison, 1979), es decir, las obras de arte fundan una temporalidad histórica ellas mismas. Esta manera de entender el desarrollo de las obras implica que cada obra establece una relación de confianza o desconfianza con las obras del pasado. Esto último se da fundamentalmente en las épocas de las vanguardias, en las que al arte se le encomienda el papel de hacer avanzar el tiempo por obra del genio y, de este modo, la cronosofía a la que da lugar es la de un tiempo discreto, constituido por períodos ordinarios, en los que no pasa nada, por mucho arte que se desarrolle, e instantes de ruptura, de revelación o de cambio radical, kairoí que determinan el curso de la historia y sus quiebros. A modo de descripción general de este proceso, podemos acudir a los conceptos clásicos de tempus y de aevum. En el pensamiento medieval, existir en el aevum es tener un principio y un final y sufrir cambios, a diferencia de la aeternitas, en la que no se da nada de esto. Estos cambios, no obstante, son accidentales, a diferencia de los que se dan en el tempus, que son cambios sustanciales. Podemos pensar que un modo clásico de entender el arte lo sitúa en el aevum, en el que hay un canon establecido, insuperable, que constituye el modelo sobre el que se operan cambios accidentales. $Y$ hay otro modo de entender el arte, vanguardista, que considera que el arte habita en el tempus, de modo que su sustancia cambia sin cesar, hasta el punto de que es imposible reconocer modelo alguno, ejemplares indiscutibles o reglas para la imitación. Esa es la razón de que el arte contemporáneo 
resulte tan complejo, precisamente porque los cambios que opera cada obra, que se pretende revolucionaria en sí misma, afectan a la sustancia misma del arte (de ahí que sea prácticamente imposible ponerse de acuerdo en una definición o en si algo es arte o no) (Castro, 2004).

\section{CONCLUSIÓN}

Cada una de las diferentes aproximaciones a la obra de arte desde el punto de vista de su temporalidad arroja aspectos nuevos de las artes en general y de las obras de arte en particular. En este artículo hemos presentado solo algunos de los diversos elementos temporales que configuran el darse y el aparecer de la obra. Hay, no obstante, otras perspectivas que tienen en cuenta el tiempo sociológico, el cósmicomítico, el eónico, el psicológico, etcétera, cuyo análisis dará lugar a comprensiones más profundas del fenómeno artístico.

\section{REFERENCIAS}

Bachelard, G. (1986). La llama de una vela. Puebla, México: Universidad Autónoma de Puebla.

Castro, S. (2002). La trama del tiempo. Salamanca, España: San Esteban.

Castro, S. (2004). La trama temporal del arte. Diánoia, 49(52), 3-26. https://doi.org/10.21898/dia.v49i52.409

Dufrenne, M. (2017). Fenomenología de la experiencia estética. Valencia, España: Publicacions de la Universitat de València.

Gadamer, H. G. (1991). La actualidad de lo bello. Barcelona, España: Paidós.

Hume, D. [1738-40] (1992). Tratado de la naturaleza humana. Madrid, España: Tecnos.

Ingarden, R. (1987). The Work of Music and the Problem of Its Identity [La obra musical y el problema de su identidad]. Berkeley, Estados Unidos: University of California Press.

Jankélévitch V. (2005). La música y lo inefable. Barcelona, España: Alpha-Decay.

Lessing, G. E. (2014). Laocconte. Ciudad de México, México: Herder.

Levinson, J. (1979). Defining art historically [Definir el arte históricamente]. British Journal of Aesthetics, 19 (3), 232-250. https://doi.org/10.1093/bjaesthetics/19.3.232

Mann, T. (1993). La Montaña Mágica. Madrid, España: Plaza \& Janés. 
Meyer, L. (1967). Music, The Arts, and Ideas: Patterns and Predictions in Twentieth Century Culture [La música, las artes y las ideas]. Chicago, Estados Unidos: University of Chicago Press. 